This is a postprint version of the following published document:

Mikes, F., González Benito, J. \& Baselga, J.

(2004). Curing of linear and crosslinked epoxy

systems: A fluorescence study with dansyl

derivatives. Journal of Polymer Science Part B:

Polymer Physics, 42 (1), pp. 64-78.

DOI: $10.1002 /$ polb.10631

(C) Wiley, 2004 


\title{
Curing of Linear and Crosslinked Epoxy Systems: A Fluorescence Study with Dansyl Derivatives
}

\author{
František Mikeš, Javier González-Benito, Juan Baselga Llidó
}

Universidad Carlos III de Madrid, Avda de la Universidad, 30-28911 Leganes, Madrid, Spain

*Correspondence to: J. B. Llidó (E-mail: jbaselga@ing. uc3m.es)

\begin{abstract}
The curing of diglycidyl ether of bisphenol A (DGEBA) with $N, N^{\prime}$-dimeth-ylethylenediamine (N,N'-DMEDA) or

ethylenediamine (EDA) was monitored by fluo-rescence spectroscopy and Fourier transform infrared (in the nearinfrared region). 5-Dimethylamino-naphthalene-1-sulfonamide (DNS) derivatives were used as probes (fluorophores added to the reaction mixture) and labels (fluorophores attached by covalent bonds to diglycidyl reactants). The term containing the ratio of the reaction rate constants for the addition of the secondary and primary amine hydrogens to the epoxide was included in the reduced reaction rate term for the autocatalyzed and catalyzed epoxide curing reactions. The changes in the integrated fluorescence inten-sities of the labels during the epoxy group conversion indicated, in some cases, the most important changes in the chemical transformations of the reaction mixture: the epoxy group conversion, during which a rapid increase in the tertiary amino group concen-tration was first observed; the gel point (for EDA); and the entry of the system into the glassy state (for $N, N^{\prime}$-DMEDA and EDA). The fluorescence probes monitored neither the gel point nor the threshold of the glassy state. For the DGEBA-N,N'-DMEDA system, a wavy dependence of the integrated fluorescence intensities of the DNS labels on the epoxy group conversion might reflect the molar concentrations of polymer homologues (referred to the initial number of moles in the system) in the reaction mixtures of the diepoxide and secondary diamine.
\end{abstract}

KEYWORDS

crosslinking; curing of polymers; fluorescence; glass transition; infrared spectroscopy; 5-dimethylaminonaphthalene-1-sulfonamide (DNS) fluorophore; labels; probes

\section{INTRODUCTION}

The properties of cured epoxide resins are known to strongly depend on the extent of cure. There exist several physicochemical methods for the characterization of the curing process. One of these methods, emission spectroscopy, has be-come very popular during the past 2 decades. The literature covering this subject includes both in-trinsic and extrinsic fluorophore techniques.

The extrinsic fluorophore technique uses three approaches:
1. A fluorophore molecule probe is added (at a low concentration) to the reaction mixture but does not participate in any reaction. ${ }^{1-3}$

2. A fluorophore label (at a low concentration) is covalently attached to the already exist-ing prepolymer molecule, but the structure of this fluorophore does not change during the curing process.

3. An added fluorescent compound contains 
reactive groups of similar (ideally the same) reactivity as the main reaction component of a formulation, and its fluorescence properties change as the curing reaction proceeds. These fluorescence property changes are caused by the modification of the chemical structure of the fluorophore and its microenvironment. ${ }^{4-9}$

The intrinsic fluorophore techniques monitor the emission of a fluorophore moiety, which is part of the reaction component. They monitor changes in its emission characteristics with the progress of the curing reaction. ${ }^{10-12}$

Sung and coworkers ${ }^{4-9,13}$ intensively studied this monitoring of cure reactions of epoxies and other network polymers.

The molecular environment can be monitored by a small molecule by means of its fluorescence characteristics and has widely been used in the past. Such molecules are usually designed to examine specific properties of their microenvironment by means of a shift in the maximum wavelength of their emission or changes in their emission intensity. ${ }^{14-19}$

To the best of our knowledge, there are only three reports comparing the use of the same fluorophore as a probe and a label for monitoring the curing process in epoxies. ${ }^{20-22}$

The main objectives of this research can be summarized as follows:

1. To compare the fluorescence behavior of the 5-dimethylamino-naphthalene-1-sulfonamide (DNS) fluorophore used as a probe and a label in epoxide resin formulations.

2. To correlate the observed changes in the integrated fluorescence intensity of the probe and the label with the extent of the epoxy group conversion $(\alpha)$.

3. To demonstrate that the monitoring of the curing of epoxide resins by changes in the fluorescence characteristics with the aforementioned fluorophore can be correlated in some cases to the most important characteristics of the curing process, such as the gel point and the entry of the system into the glassy state.

\section{EXPERIMENTAL}

\section{Materials}

Diglycidyl ether of bisphenol A (DGEBA; molecular weight $=348 \mathrm{~g} / \mathrm{mol}$; Aldrich) was purified according to a previously published procedure..$^{23}$ It was distilled in vacuo, recrystallized from acetone and methanol, carefully dried, and stored under nitrogen $\left(\mathrm{mp}=42.5-43.6{ }^{\circ} \mathrm{C}\right)$. The epoxy content was 5.86 equiv/ $/ \mathrm{kg}$, as determined by acid titration $^{24}$ (weight per equivalent $=170.6$ g/equiv). $N, N^{\prime}$-Dimethylethylenediamine ( $N, N^{\prime}$ DMEDA) and ethylenediamine (EDA) were Aldrich products used as received.

Preparation of the Probe and Label Precursor: 5Dimethylaminonaphthalene-1-sulfonamide Derivatives (Dansyl Derivatives)

5-Dimethylaminonaphthalene-1-[ $N$-(di- $n$-butyl)]sulfonamide (DNSd-Bu; Scheme 1) was prepared by the reaction of 5-dimethylaminonaphthalene1-sulfonyl chloride (dansyl chloride)with an excess of di-n-butylamine in chloroform. The details and characterization of the compound have been described elsewhere. ${ }^{22}$

The label precursor 5-dimethylaminonaphthalene-1-[N-(2-aminoethyl)] sulfonamide (DNS EDA; Scheme 1) was prepared by the reaction of dansyl chloride with a solution of EDA in chloroform. The details are described elsewhere. ${ }^{22}$

\section{Labeling of the Epoxide Component}

The labeling of the epoxide component (DGEBA) was performed by the reaction with DNS EDA. In a typical labeling experiment, DGEBA(48 g, $\sim 0.276 \mathrm{~mol}$ of epoxy groups) was heated at $60^{\circ} \mathrm{C}$ under stirring with DNS EDA $(0.087 \mathrm{~g}, 2.96$ $\times 10^{-4} \mathrm{~mol}$ ) for $6 \mathrm{~h}$. At the end of the reaction time, according to thin-layer chromatography and size exclusion chromatography, the reaction mixture did not contain any unreacted DNS EDA. We may assume that the DNS structural unit is attached at the end of the ethylene spacer and that this spacer is anchored to the addition product of two DGEBA molecules.

\section{Analytical Methods}

\section{Differential Scanning Calorimetry (DSC)}

A PerkinElmer DSC-7 differential scanning calorimeter was used for the measurements. Samples weighing 5-15 mg were measured.

The glass-transition temperatures $\left(T_{\mathrm{g}}\right.$ 's) for the stoichiometric reaction mixtures were determined by DSC. The curing of the DGEBAEDA mixture was carried out in the DSC appa- 
<smiles>CCCCN(CCCC)S(=O)(=O)c1cccc2c(N(C)C)cccc12</smiles>

DNSd-Bu<smiles>CN(C)c1cccc2c(S(=O)(=O)NCCN)cccc12</smiles><smiles>NCCN</smiles>

EDA<smiles>CNCCNC</smiles>

N,N'- DMEDA<smiles>CN(C)c1cccc2c(S(=O)(=O)NCCN(CC(O)COc3ccc(C(C)(C)c4ccc(OCC5CO5)cc4)cc3)CC(O)COc3ccc(C(C)(C)c4ccc(OCC5CO5)cc4)cc3)cccc12</smiles>

Labeled DGEBA

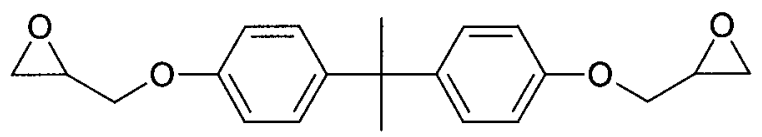

DGEBA

Scheme 1. Molecular formulas.

ratus at $40,60,70$, and $80{ }^{\circ} \mathrm{C}$ and at $20{ }^{\circ} \mathrm{C}$ in a thermostat outside of the DSC apparatus. The samples of DGEBA- $N, N^{\prime}$-DMEDA were cured in the DSC apparatus at $40{ }^{\circ} \mathrm{C}$ only. The ultimate conversion was achieved with a dynamic scan $\left(30-200{ }^{\circ} \mathrm{C}\right)$ at a scanning rate of $5{ }^{\circ} \mathrm{C} / \mathrm{min}$. DSC thermograms were obtained by temperature scanning at $10^{\circ} \mathrm{C} / \mathrm{min}$. The glass transition appeared as an endothermic shift over a temperature interval in the DSC scan. In this study, $T_{\mathrm{g}}$ was taken as the midpoint of the step transition and was evaluated with a computer program supplied by PerkinElmer.

\section{Fourier Transform Infrared (FTIR) Spectroscopy}

A PerkinElmer GX FTIR spectrometer was used to monitor the rate of disappearance of the epoxide ring and the primary amine group. All spectra were collected in the near-infrared region (7000$4000 \mathrm{~cm}^{-1}$ ). Each spectrum was obtained, according to the rate of the curing reaction, by the averaging of 4-20 scans at a $4-\mathrm{cm}^{-1}$ resolution with a scanning rate of $0.2 \mathrm{~cm} / \mathrm{s}$. Measurements were carried out isothermally at $20-80{ }^{\circ} \mathrm{C}$ with a Specac temperature controller. The epoxide formulations were cured in disposable cells made from 
microscope glass slide plates with an optical path of 0.7-1.0 mm determined by the thickness of a Teflon spacer.

The main spectral bands of interest for monitoring the cure reactions and their assignments are in general agreement with those previously reported. ${ }^{25-27}$ The main features of the spectra are (1) a decrease in the epoxy band around 4530 $\mathrm{cm}^{-1},(2)$ a decrease in the primary amine group band at $4938 \mathrm{~cm}^{-1}$, and (3) an increase in the hydroxyl bands in the region around $4800 \mathrm{~cm}^{-1}$. The most significant feature is the appearance of an isosbestic point between the epoxy and hydroxyl group bands. This indicates that Beer's law is obeyed over a wide range of conversions. ${ }^{28}$ The values of the integrated absorbance corresponding to ultimate curing were obtained after at least $3 \mathrm{~h}$ of curing at $150\left(N, N^{\prime}\right.$-DMEDA $)$ or $200{ }^{\circ} \mathrm{C}$ (EDA). The analysis consisted of measuring the integrated absorbances at two specified wave numbers: one corresponding to the changing epoxy peak and the other corresponding to an invariant band at $4623 \mathrm{~cm}^{-1}$.

\section{Ultraviolet-visible (UV-vis) Spectroscopy}

All the spectra were taken on a PerkinElmer Lambda 14P UV-vis spectrometer. The spectra of the components and the reaction mixture were measured in homemade cells from microscope glass slide plates or spectrometric-grade poly(methyl methacrylate). The optical path was between 0.6 and $1.0 \mathrm{~mm}$ and was determined by the thickness of a Teflon spacer. The wavelength cutoff absorption for the glass used was $350 \mathrm{~nm}$. The homemade cells prepared from spectrometricgrade poly(methyl methacrylate) were transparent in the spectral region of $275-700 \mathrm{~nm}$.

\section{Fluorescence Measurements}

Steady-state uncorrected fluorescence spectra were recorded on a PerkinElmer LS 50B luminescence spectrometer. The samples of the neat epoxide resin formulations, labeled, containing a probe, or unlabeled, were recorded with a frontface $\left(60^{\circ} / 30^{\circ}\right)$ geometry in disposable thermostated cells made from microscope slide glass plates. The time-dependent changes in the emission spectra with the progress of the curing reaction were recorded with the same fluorometer provided with a homemade program. From the emission spectra, the integrated fluorescence intensities were obtained.

\section{Gel-Point Determination}

The conversion at the gel point for DGEBA-EDA was determined with sol-gel analysis. The curing reaction at a chosen temperature took place in sealed Teflon tubing (inner diameter $=0.4 \mathrm{~cm}$; Legris, France) with approximately $1 \mathrm{~g}$ of the reaction mixture. After a selected time interval, the sample was cooled with liquid nitrogen, crushed, and extracted first with a chloroform/ acrylonitrile $(1: 1 \mathrm{w} / \mathrm{w})$ mixture and then with chloroform in a Soxhlet extractor. The addition of the hydrogens of the amino groups to acrylonitrile prevented any possible reaction during the initial extraction. ${ }^{29,30}$ The critical conversion at the gel point was determined from a plot of $\alpha$ versus the gel content by extrapolation to a zero gel content. In the stoichiometric reaction mixtures, the addition of acrylonitrile to block the amino groups did not substantially influence the amount of the gel fraction.

\section{RESULTS AND DISCUSSION}

\section{Labeling of an Epoxide Component: UV-vis and Fluorescence Spectra}

The epoxy groups react readily with the primary and secondary aliphatic amino groups. Labeled DGEBA contains a low concentration of the DGEBA addition product containing the dansyl fluorophore in the side chain (Scheme 1).

The addition reaction of the primary amino group of the label precursor DNS EDA to the epoxy group does not shift the absorption of the dansyl fluorophore in the UV-vis region.

The fluorescent label and probe used in the aforementioned diepoxide-diamine systems have an excitation spectral range of $320-380 \mathrm{~nm}$. Because of the overlap of the UV-vis absorption bands of the epoxide reaction mixtures and the fluorescent label or probe, their UV-vis absorption spectra have been measured. Two important conclusions can be drawn. First, there are negligible changes in the absorption spectra in the long-wavelength region $(300-380 \mathrm{~nm})$ for the labeled or probe-containing reaction mixtures with the progress of curing (the extent of $\alpha=0-0.80$ ). Second, the stoichiometric DGEBA-diamine reaction mixture has a cutoff absorption around 335 $\mathrm{nm}$; this cutoff absorption shifts to $350 \mathrm{~nm}$ when $\alpha$ reaches 0.65 . The same reaction mixtures labeled with the DNS fluorophore absorb strongly between 310 and $390 \mathrm{~nm}$. This absorption is 
caused by the DNS fluorophore. To minimize the emission by the DGEBA-diamine reaction mixtures, we have used a relatively high concentration of the DNS fluorophore. The fraction of light absorbed by the DNS fluorophore is close to unity, and the observed emissions in the curing experiments are due only to the DNS fluorophore. Under the reaction conditions employed in this report, the decomposition of the fluorophore occurs neither for the probe nor for the label. There is no appreciable reabsorption of the emitted radiation despite a rather high optical density due to a large Stokes shift of the DNS fluorophore in these reaction media. The excitation wavelength in all cases is $350 \mathrm{~nm}$.

For fluorescence monitoring of the curing progress in stoichiometric mixtures of DGEBA and $N, N^{\prime}$-DMEDA or EDA, the concentration of the DNS fluorophore is $4.92 \times 10^{-3}$ or $5.67 \times 10^{-3}$ $\mathrm{mol} / 1000 \mathrm{~g}$ of reaction mixture, respectively. In the nonstoichiometric reaction mixtures of DGEBA and EDA, the concentration of the DNS fluorophore is proportionally higher or lower.

\section{Curing of the DGEBA- $N, N^{\prime}$-DMEDA and DGEBA- EDA Reaction Mixtures}

The curing parameters of the systems DGEBAEDA and DGEBA- $N, N^{\prime}$-DMEDA are described. Some physicochemical characterization has to be repeated because of conflicting results published in the past. ${ }^{31,32}$

\section{Extent of the Curing and the Curing Kinetics of the Epoxide Reaction with Primary and Secondary Diamines}

The aim of this work is not to carry out a detailed kinetic analysis of the curing reaction for the DGEBA-EDA or DGEBA- $N, N^{\prime}$-DMEDA systems. In this part, we intend to show on the basis of a simple mechanistic kinetic model the stages of the curing reaction: (1) the stage of the curing reaction governed by a chemical reaction, (2) the region controlled by diffusion in which vitrification is in progress, and (3) the threshold at which the system enters the vitrified region. These regions are correlated with the changes in the integrated fluorescence intensity.

In early studies, it was found that hydroxyl groups catalyze the addition reaction of the amino groups to the epoxy group. Mechanistic kinetic models based on this observation were pro- posed. ${ }^{33}$ To improve the mechanistic approach, researchers considered other possible reactions, such as the homopolymerization of the epoxy groups and etherification. Also, the different reactivities of the primary and formed secondary amino groups with the epoxy groups were taken into account. Nevertheless, the extended mechanistic models are not able to exactly fit the experimental results obtained for several epoxy-amine systems. Many authors have used different types of phenomenological equations to fit their experimental data. One example of this approach is the work of Sourour and Kamal. ${ }^{34}$

An improvement in mechanistic models arose from the consideration that different hydrogenbonded transition complexes may be formed; their formation and dissociation during the reaction might control the kinetics. ${ }^{35,36} \mathrm{~A}$ general kinetic scheme was employed by Flammersheim ${ }^{37}$ to rationalize the experimental results obtained for different epoxy-amine systems. The experimental data were analyzed with the modified kinetic equation (eq 1) of Horie et al. ${ }^{31}$ The model leading to eq 1 assumes that external catalysts (HX), including impurities initially present in the system, can also act as catalysts of this reaction. The second path is catalyzed by the hydroxyls generated during the reaction (autocatalytic path). A noncatalytic mechanism with a higher activation energy during low-temperature isothermal curing is not considered in this model. The epoxide is activated by the formation of a hydrogen bond between the oxygen of the oxirane ring and any proton donor. ${ }^{33}$ However, the reaction scheme considers neither the equilibrium concentrations of particular components nor other hydrogenbonded complexes that may be formed. The molecule $(\mathrm{HX})_{0}$ initially present in the system and the reaction products containing the pendant hydroxyl groups on the backbone (HA) $)_{A}$ act as true catalysts and are not consumed in any side reactions. The reduced reaction rate containing a $\Delta n$ term is given by eq 1 :

$$
\frac{\frac{d \alpha}{d t}}{(1-\alpha)(B-\alpha)\left(1+\frac{2 a_{2} \Delta n}{\left(2 a_{1}+a_{2}\right)}\right)}=\frac{k_{1} e_{0}^{2}}{2} \alpha+\frac{k_{1}^{\prime} e_{0} c_{0}}{2}
$$

where $B$ is equal to $2 a_{1}^{0} / e_{0}$ (for the stoichiometric reaction mixture $B=1$ ). $a_{1}^{0}$ and $e_{0}$ are the initial 
concentrations of the primary amine and epoxide, respectively. $k_{1}$ and $k_{1}^{\prime}$ are the reaction rate constants for the autocatalyzed and catalyzed reactions of the epoxide with the primary amine, respectively. The concentrations of the primary and secondary amines at $\alpha$ are $\alpha_{1}$ and $a_{2}$, respectively. $c_{0}$ represents the concentration of $(\mathrm{HX})_{0} . \Delta n$ is defined as follows:

$$
\begin{gathered}
\frac{k_{2}}{k_{1}}=\frac{k_{2}^{\prime}}{k_{1}^{\prime}}=n \\
\Delta n=n-1 / 2
\end{gathered}
$$

$k_{2}$ and $k_{2}^{\prime}$ are the reaction rate constants of the autocatalyzed and catalyzed reactions of epoxide with the secondary amine, respectively.

The concentrations of the epoxy and primary amino groups have been directly evaluated from the experimental data, and the concentrations of the secondary and tertiary amines have been calculated from the mass balances. For the stoichiometric mixture of the diepoxide and primary diamine, the concentration of the secondary amine $\left(a_{2}\right)$ is

$$
a_{2}=e_{0}(\beta-\alpha)
$$

The concentration of the tertiary amine $\left(a_{3}\right)$ is

$$
a_{3}=e_{0}\left(\alpha-\frac{\beta}{2}\right)
$$

where $\beta$ is the conversion of the primary amino groups $\left(\beta=\frac{a_{1}^{0}-a_{1}}{a_{1}^{0}}\right)$.

The ratio of the rate constants $k_{2} / k_{1}$ is 0.39 at 40 and $60{ }^{\circ} \mathrm{C} .{ }^{38}$ At $20{ }^{\circ} \mathrm{C}, k_{2} / k_{1}=0.42$ was evaluated with the method of Paz-Abuin et al. ${ }^{38}$

For the stoichiometric reaction of the secondary diamine (e.g., $N, N^{\prime}$-DMEDA) with a diepoxide, eq 1 is reduced to

$$
\frac{\frac{d \alpha}{d t}}{(1-\alpha)^{2}}=k_{2} e_{0}^{2} \alpha+e_{0} k_{2}^{\prime} \mathbf{c}_{0}
$$

$k_{2}$ and $k_{2}^{\prime}$ are the reaction rate constants for the autocatalyzed and catalyzed additions of the secondary amine hydrogens of $N, N^{\prime}$-DMEDA to the epoxy group.
The aforementioned model of Horie has been used to analyze isothermal low-temperature data obtained for the curing of diepoxides with aliphatic primary and mainly aromatic diamines. For an interpretation to both isothermal and dynamic results, a further kinetic model is postulated. First, the reactivity of the primary $\left(k_{1}\right)$ and secondary $\left(k_{2}\right)$ amino hydrogens in amines is the same. Second, the reaction takes place by two competitive paths: one is catalyzed by the hydroxyl groups initially present in DGEBA and those generated during the reaction (the reaction rate constant $k$ ), and the other is a noncatalytic mechanism (the reaction rate constant $k^{\prime}$ ) with a higher activation energy. In this case, the reduced reaction rate for the stoichiometric reaction mixture is

$$
\frac{\frac{d \alpha}{d t}}{(1-\alpha)^{2}}=k^{\prime} e_{0}+k^{\prime} e_{0} c_{0}+k e_{0}^{2} \alpha
$$

The rate reaction constants $k$ and $k^{\prime}$ can be determined from the slope and intercept of the dependence of the reduced reaction rate versus $\alpha$, respectively.

The addition of the secondary amine hydrogens of $N, N^{\prime}$-DMEDA to the epoxy group of DGEBA was carried out at $20,30,40,60$, and $80{ }^{\circ} \mathrm{C}$. Figure 1 shows the dependence of $\alpha$ on the curing time at $20,30,40$, and $60{ }^{\circ} \mathrm{C}$.

The dependence of $T_{\mathrm{g}}$ on $\alpha$ has been determined (Fig. 2). The curing goes to completion. The reduced reaction rate (eq 4) increases linearly with $\alpha$ at 30 and $60{ }^{\circ} \mathrm{C}$ up to a $50 \%$ conversion, as shown in Figure 2. The departure from linearity observed at higher conversions is due to the limitations, discussed previously, of the kinetic model employed. From the slope of the linear part of the curve (Fig. 2), the rate constant $k_{2}$ can be determined at different temperatures. The intercepts give values of $k_{2}^{\prime} c_{0}$. The rate constants for the reaction of DGEBA with $N, N^{\prime}$-DMEDA are summarized in Table 1.

Important differences in the behavior of this system can be observed at different reaction temperatures for high values of $\alpha$ (Fig. 2). A $T_{\mathrm{g}}$ of $30{ }^{\circ} \mathrm{C}$ is attained around a $90 \%$ conversion of the epoxy groups [cf. Fig. 2(c)]. At approximately the same conversion, a decrease in the reduced reaction rate for the $30{ }^{\circ} \mathrm{C}$ isothermal reaction can be observed, indicating the onset of vitrification. ${ }^{39}$ A curing temperature $\left(T_{\text {cure }}\right)$ of 


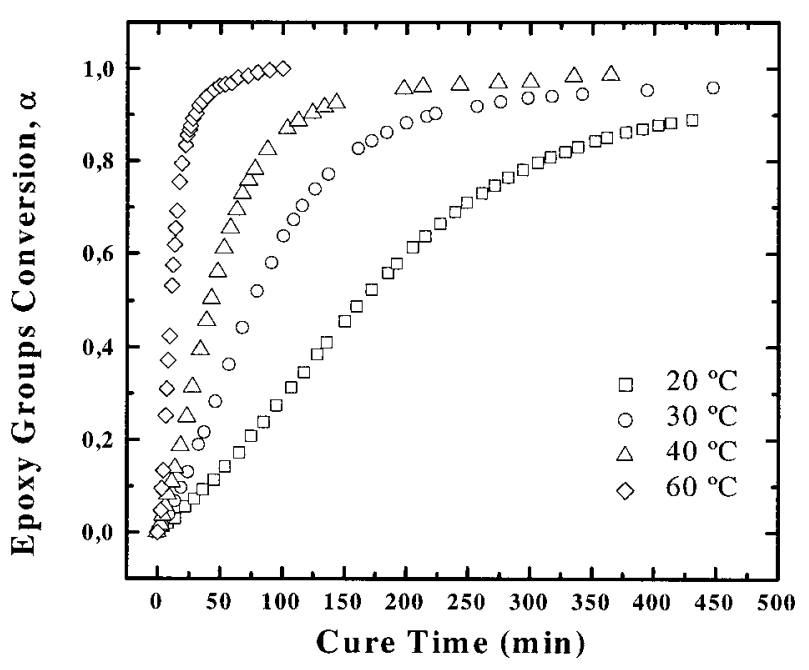

Figure 1. Dependence of $\alpha$ on the curing time for the stoichiometric reaction mixture DGEBA- $N, N^{\prime}$-DMEDA. $T_{\text {cure }}$ was $20,30,40$, or $60^{\circ} \mathrm{C}$ (FTIR analytical method).

$60{ }^{\circ} \mathrm{C}$ is above $T_{\text {go }}$ (glass transition temperature at complete conversion $)\left(\sim 50{ }^{\circ} \mathrm{C}\right)$. Therefore, no decrease in the reduced reaction rate takes place in a reaction at $60{ }^{\circ} \mathrm{C}$.

In the liquid or rubbery state, the diffusion rate constant is much higher than an Arrhenius rate constant, so the polyaddition rate is chemically controlled.

For an isothermal transformation that occurs when a general temperature $T$ is equal to $T_{\text {cure }}$, the reaction times are unequivocally related to the conversion. ${ }^{40,41}$ Outside the vitrification region, a monoexponential decrease in the reaction time corresponding to $\alpha\left(t_{\alpha}\right)$ with $T_{\text {cure }}$ can be observed only when the activation energies of elementary reactions are equal or if one of the terms of eq $1 \mathrm{and} /$ or eq 4 prevails over the other (usually the first term over the second term). In the vitrification region, a sharp drop in the reaction rate brings about a large increase in the curing time. In the liquid and rubbery state, the dependence of $\ln t_{\alpha}$ versus $1 / T_{\text {cure }}$ will be linear under the aforementioned conditions, and an activation energy may be obtained. At higher conversions or lower $T_{\text {cure }}$ 's, the system may enter into the vitrification region. Here, the rate constant can be a function of conversion when it is under combined chemical and diffusion control. ${ }^{42} \mathrm{~A}$ deviation from the linear dependence of $\ln t_{\alpha}$ versus $1 / T$ is expected.

For the DGEBA- $N, N^{\prime}$-DMEDA system and $\alpha$ up to approximately 0.75 , dependencies of $\ln t_{\alpha}$ on $1 / T_{\text {cure }}$ are linear at $T_{\text {cure }}=20-60{ }^{\circ} \mathrm{C}$ and are

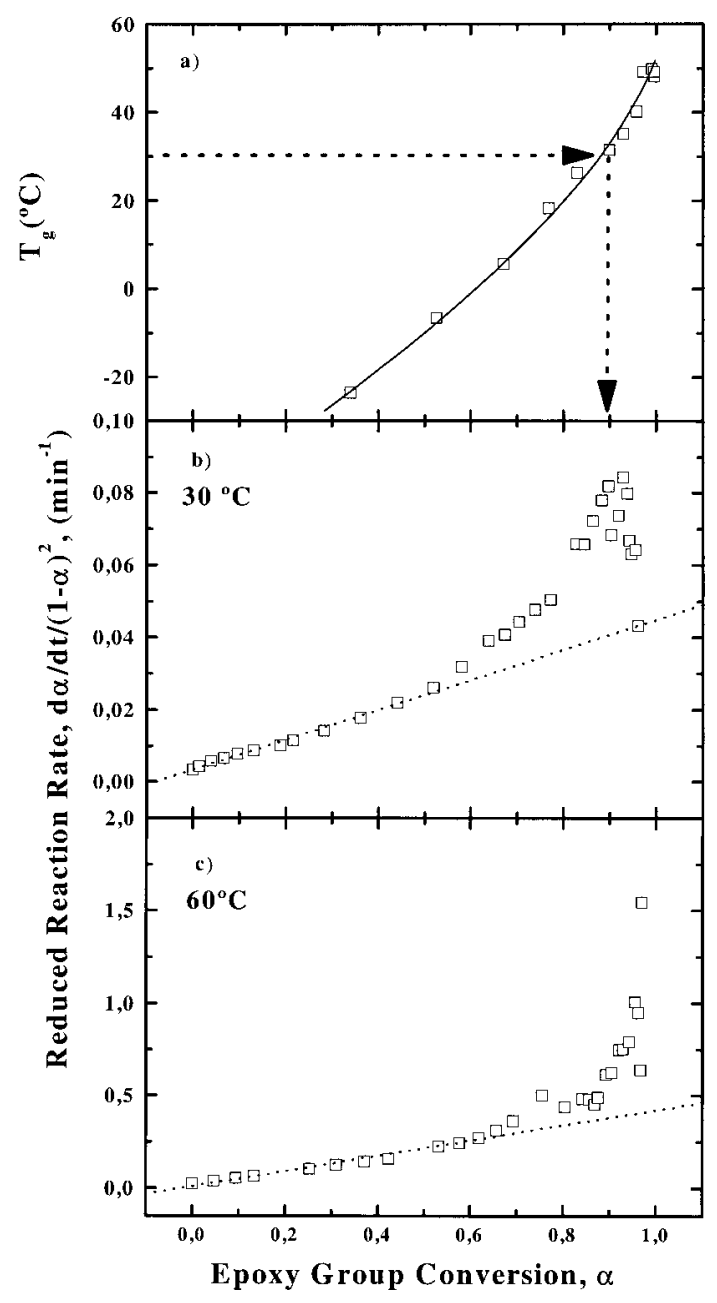

Figure 2. Dependence of (a) $T_{\mathrm{g}}$ and (b,c) the reduced reaction rate $\left[(d \alpha / d t) /(1-\alpha)^{2}\right]$ at 30 and $60{ }^{\circ} \mathrm{C}$, respectively, on $\alpha$ for the stoichiometric reaction mixture DGEBA- $N, N^{\prime}$-DMEDA.

parallel for different values of $\alpha$ (Fig. 3). The overall apparent Arrhenius activation energy evaluated from experimental data is $59 \mathrm{~kJ} / \mathrm{mol}$.

Table 1. Reaction Rate Constants for the Reaction of DGEBA with $N, N^{\prime}$-DMEDA

\begin{tabular}{ccc}
\hline $\begin{array}{c}\text { Reaction } \\
\text { Temperature } \\
\left({ }^{\circ} \mathrm{C}\right)\end{array}$ & $\begin{array}{c}k_{2} \times 10^{4} \\
\left(\mathrm{~kg}^{2} / \mathrm{mol}^{2} \mathrm{~min}\right)^{\mathrm{a}}\end{array}$ & $\begin{array}{c}k_{2}{ }^{\prime} c_{\mathrm{o}} \times 10^{4} \\
(\mathrm{~kg} / \mathrm{mol} \mathrm{min})^{\mathrm{b}}\end{array}$ \\
\hline 20 & 8.9 & 4.0 \\
30 & 19.7 & 7.4 \\
40 & 33.1 & 15.2 \\
60 & 185.4 & 29.1 \\
\hline
\end{tabular}

${ }^{\mathrm{a} A c t i v a t i o n ~ e n e r g y ~}=58.8 \mathrm{~kJ} / \mathrm{mol}$.

${ }^{\mathrm{b}}$ Activation energy $=40.6 \mathrm{~kJ} / \mathrm{mol}$. 


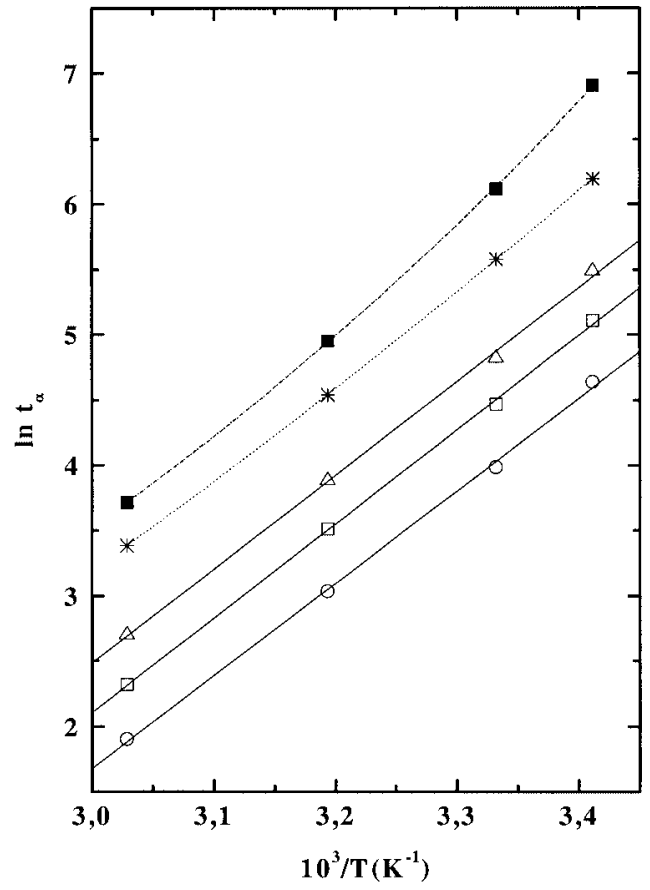

Figure 3. Dependence of $\ln t_{\alpha}$ on $1 / T$ [where $T$ is the curing temperature $(\mathrm{K})$ ] for the stoichiometric reaction mixture DGEBA- $N, N^{\prime}$-DMEDA. $\alpha$ was $(\bigcirc) 0.3,(\square) 0.5$, ( $\triangle) 0.7,(*) 0.9$, or $(\square) 0.94$

This value is in fairly good agreement with the overall apparent activation energy for the curing of epoxides with amines obtained by other methods and with the activation energy for the autocatalyzed addition reaction (Table 1 ). The rather low value of the activation energy evaluated for the catalyzed reaction is caused by a larger scatter of the experimental data.

The curing of the stoichiometric mixture DGEBA-EDA was carried out at 20, 40, 60, 70, and 80 ${ }^{\circ} \mathrm{C}$, and that of the nonstoichiometric mixtures was carried out at $40{ }^{\circ} \mathrm{C}$. In Figure 4 , the dependence of the epoxy and primary amino group conversions is shown, as determined by FTIR, along with the dependence of the secondary and tertiary amino group concentrations in the reaction mixture on the curing time at $60{ }^{\circ} \mathrm{C}$ according to eqs $3 \mathrm{a}$ and $3 \mathrm{~b}$. In the absence of a substitution effect, the evolution of the primary, secondary, and tertiary amino group concentrations should follow the following equations: $a_{1}{ }^{*}=a_{1}^{0}(1-\alpha)^{2}, a_{2}{ }^{*}$ $=2 a_{1}^{0} \alpha(1-\alpha)$, and $a_{3}^{*}=a_{1}^{0} \alpha^{2}$ [Fig. 4(b), solid lines]. These equations do not provide a good fit of the experimental curves. The substantially higher experimental concentration of the secondary amino groups at the maximum suggests that the ratio $k_{2} / k_{1}$ has to be lower than 0.5 . At $\alpha=0.2$, at which the increase in the experimental $a_{3}$ concentration is first detected, its concentration is $0.04 a_{1}^{0}$ for $k_{2} / k_{1}=0.5$. For our system, the concentration of the tertiary amino groups at $\alpha=0.2$ is supposed to be even lower than $0.04 a_{1}^{0}$ and is not detected within the experimental error associated with the use of mass balances together with the primary information from the FTIR spectra.

An apparent onset of the concentration of the tertiary amino groups takes place at approximately the same value of $\alpha(\sim 0.2$; Fig. 4$)$ at all temperatures. The ratio of the rate constants $k_{2} / k_{1}$ is nearly independent of temperature in the

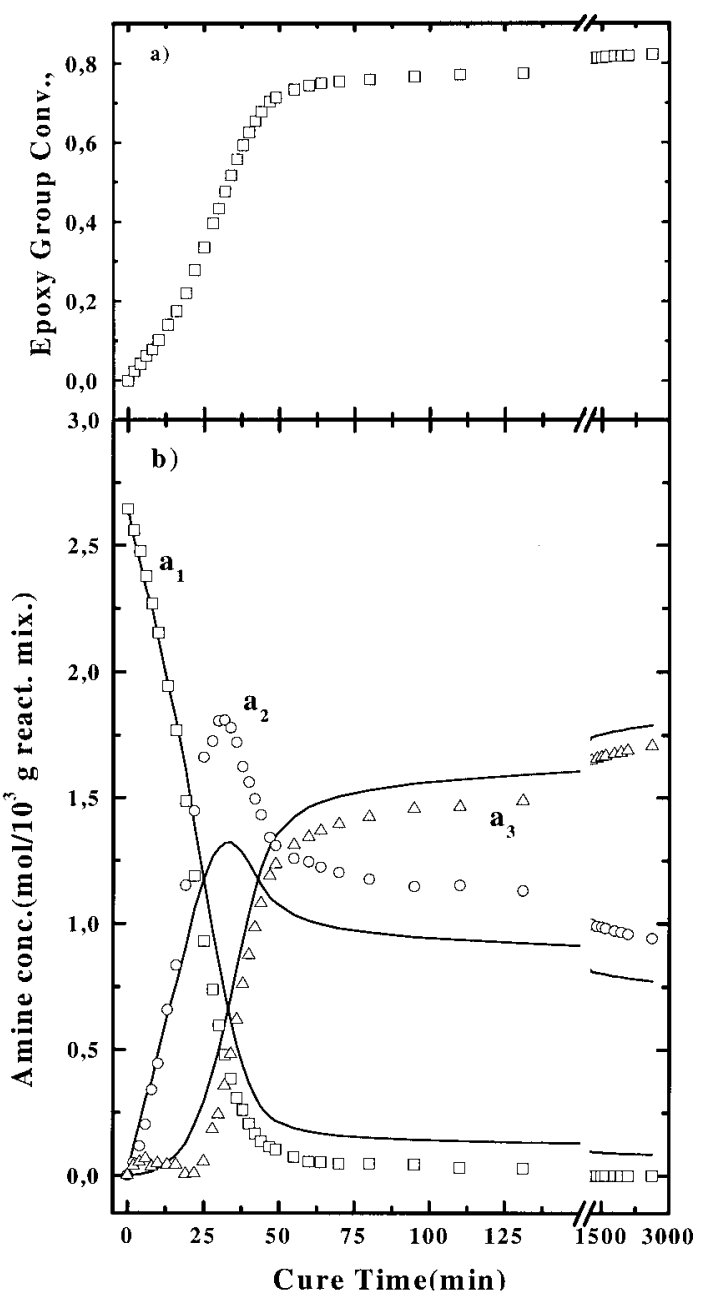

Figure 4. Time dependence of (a) $\alpha$ and (b) the primary $\left(a_{1}\right)$, secondary $\left(a_{2}\right)$, and tertiary $\left(a_{3}\right)$ amino group concentrations on the curing time for the stoichiometric reaction mixture DGEBA-EDA at $T_{\text {cure }}=60{ }^{\circ} \mathrm{C}$. The symbols show the experimental data, and the solid lines show the calculated values for $k_{2} / k_{1}=0.5$ (see the text). 


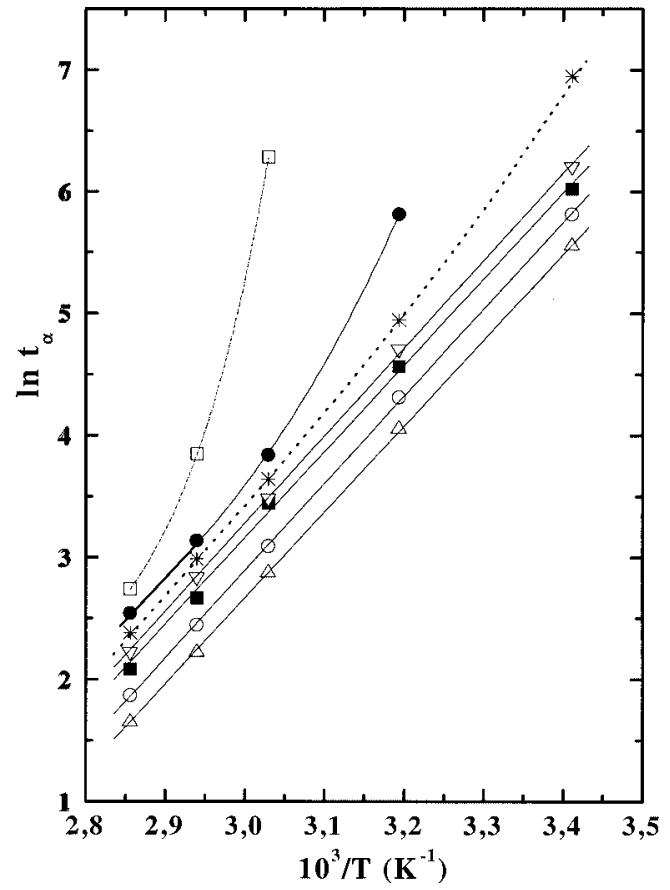

Figure 5. Dependence of $\ln t_{\alpha}$ on $1 / T$ for the stoichiometric reaction mixture DGEBA-EDA (for $t_{\alpha}, T$, and $\alpha$, see Fig. 3). $\alpha$ was $(\triangle) 0.2,(\bigcirc) 0.3,(\square) 0.4,(\nabla) 0.5,(*)$ 0.6 , (๑) 0.7 , or $(\square) 0.8$

interval of $T_{\text {cure }}=20-80{ }^{\circ} \mathrm{C}$. The gel-point conversion of the epoxy groups at 40 and $60{ }^{\circ} \mathrm{C}$ is for the same reason constant and is equal to 0.56 and 0.57 , respectively. According to the Flory-Stockmayer theory, $\alpha_{\text {gel }}$ is 0.577 without substitution effects $\left(k_{1} / k_{2}=0.5\right)$ and in the absence of any other nonideality. ${ }^{40,41}$

From the dependence of $\ln t_{\alpha}$ on $1 / T\left(20-80^{\circ} \mathrm{C}\right)$ for $\alpha=0.35$, the evaluated overall apparent Arrhenius activation energy is $54.6 \mathrm{~kJ} / \mathrm{mol}$. The dependencies of $\ln t_{\alpha}$ on $1 / T$ are linear for $\alpha \sim 0.2-$ 0.5 in the temperature interval of $20-80{ }^{\circ} \mathrm{C}$ (Fig. $5)$. For $\alpha$ values of $0.6-0.7$, these dependencies do not obey a linear relationship; this indicates that the system has entered into the vitrification region at temperatures of approximately 50 and 65 ${ }^{\circ} \mathrm{C}$, respectively. Vitrification is in progress for $\alpha$ $=0.8$ in the entire temperature interval of $20-80$ ${ }^{\circ} \mathrm{C}$. The $T_{\mathrm{g}}$ values for the DGEBA-EDA mixture are more scattered (shown later in Figs. 7-9). This is attributed to the nearness of $T_{\mathrm{g}}$ and the residual exotherm appearing (for $\alpha \sim 0.5-0.9$ ) in the DSC traces. Poor reproducibility in the determination of $T_{\mathrm{g}}$ at the ultimate conversion is caused by the rather small difference between the heat capacities of the nearly fully cured sample in the rubbery and glassy states. ${ }^{32}$
Figure 6 shows the experimental values of the reduced reaction rates at $20{ }^{\circ} \mathrm{C}$ plotted as $(d \alpha / d t) /(1-\alpha)^{n}$ versus $\alpha$ for $n=1.5, n=2$ (eq 5 ), and $n=2$ (Horie's model, eq 1). In the first part of this dependence, the best linear fit is found for $n=1.5$, as pointed out by several authors $^{36,43}$ for epoxide systems, but the connection with the chemistry of the process is lost. The reduced reaction rate versus $\alpha$ [eq 1 ; Figs. 7(b), 8(b), and 9(b)] obeys at low conversions a fairly good linear relationship (correlation coefficient $\sim 0.99$, higher than the original Horie plot. ${ }^{31}$ ) A decrease in the reduced reaction rate coincides approximately with $\alpha$ at which the $T_{\mathrm{g}}$ [Figs. 7(a), 8(a), and 9(a)] of the reaction mixture is equal to $T_{\text {cure }}$. Close to this temperature, the reaction system enters the vitrification region. From the slope and intercept at different temperatures, the reaction rate constants $k_{1}$

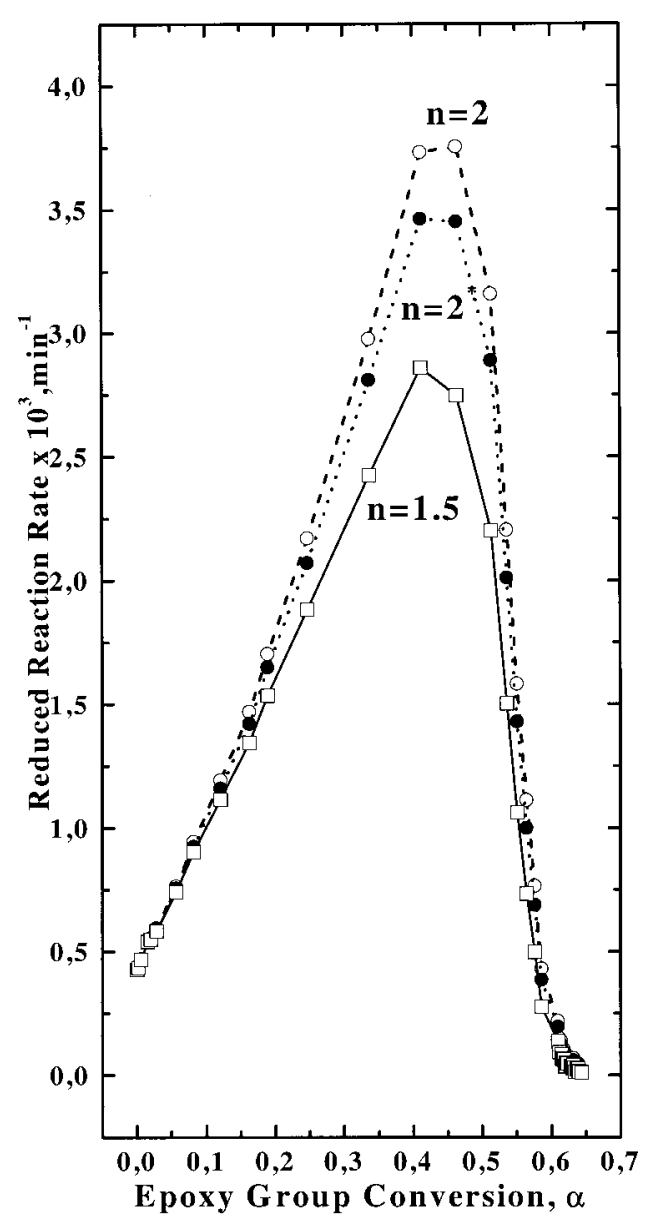

Figure 6. Dependence of the reduced reaction rate on $\alpha$ at $T_{\text {cure }}=20{ }^{\circ} \mathrm{C}$ for the stoichiometric reaction mixture DGEBA-EDA: $(\bigcirc)$ according to eq $5,(\bigcirc)$ according to eq 1 , and $(\square)(d \alpha / d t) /(1-\alpha)^{1.5}$. 


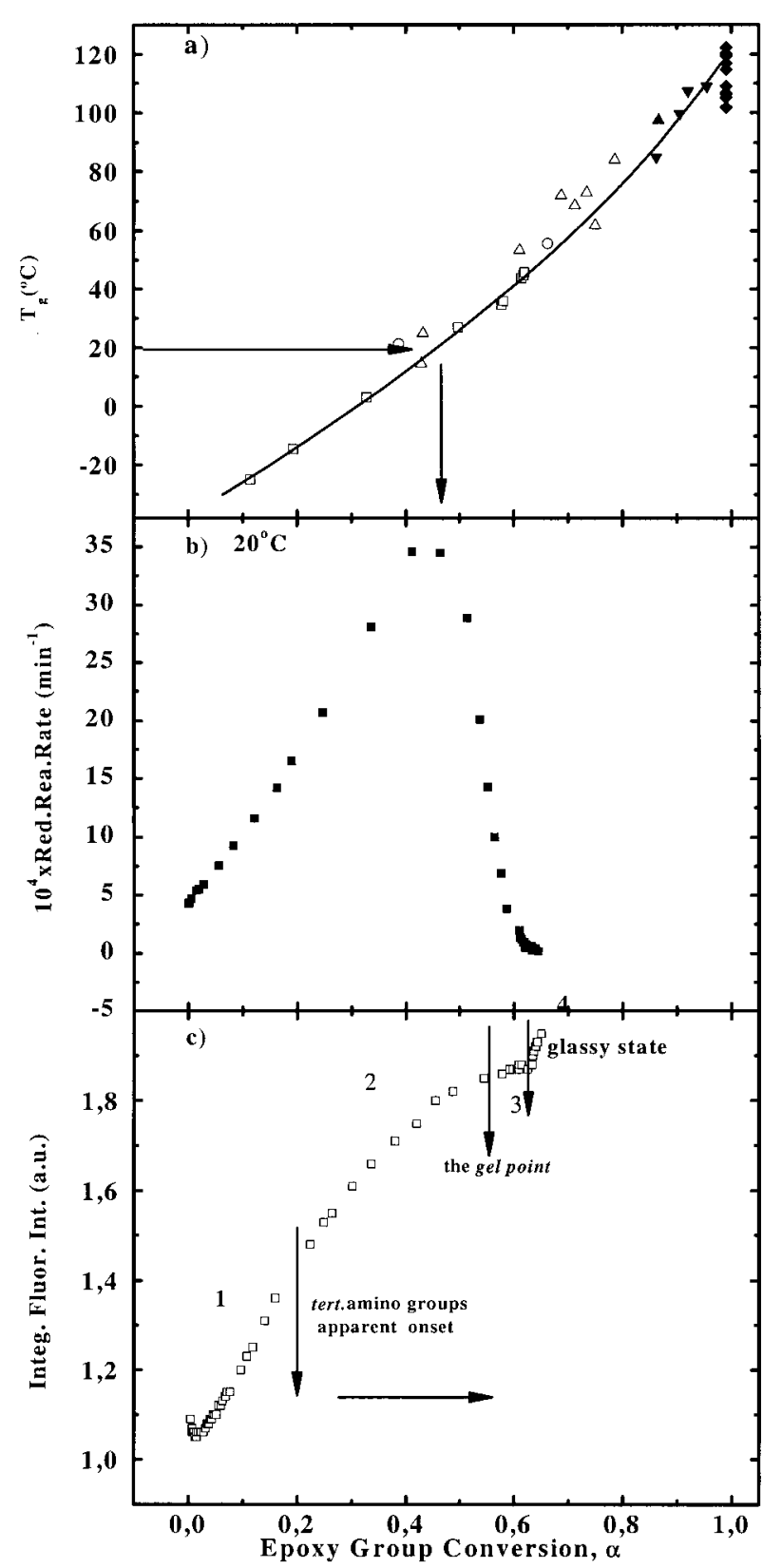

Figure 7. Dependence of (a) $T_{\mathrm{g}}$, (b) the reduced reaction rate, and (c) the integrated fluorescence intensity for the DNS label on $\alpha$ at $T_{\text {cure }}=20^{\circ} \mathrm{C}$ for the stoichiometric reaction mixture DGEBA-EDA. $T_{\text {cure }}$ was $(\square)$ 20, (○) 40, $\triangle(\triangle) 60,(\Delta) 70$, or $(\boldsymbol{\nabla})$ 80. Diamonds indicate ultimate curing by a $30-200^{\circ} \mathrm{C}$ DSC scan at $5^{\circ} \mathrm{C} / \mathrm{min}$.

and $k_{1}^{\prime} c_{0}$ have been evaluated; $k_{2}$ has been calculated according to eq 2 a (Table 2). Comparing our results with those of Horie et al. ${ }^{31}$ and Wiliams et al., ${ }^{32}$ we find that the agreement is reasonable, considering that $\alpha$ is determined by FTIR and calorimetry.
The Arrhenius activation energies for the elementary rate constants and, consequently, for the overall apparent activation energy are in fairly good agreement. It can be suggested that these elementary reactions proceed by the same mechanism and are not controlled by diffusion in the early stages of conversion.

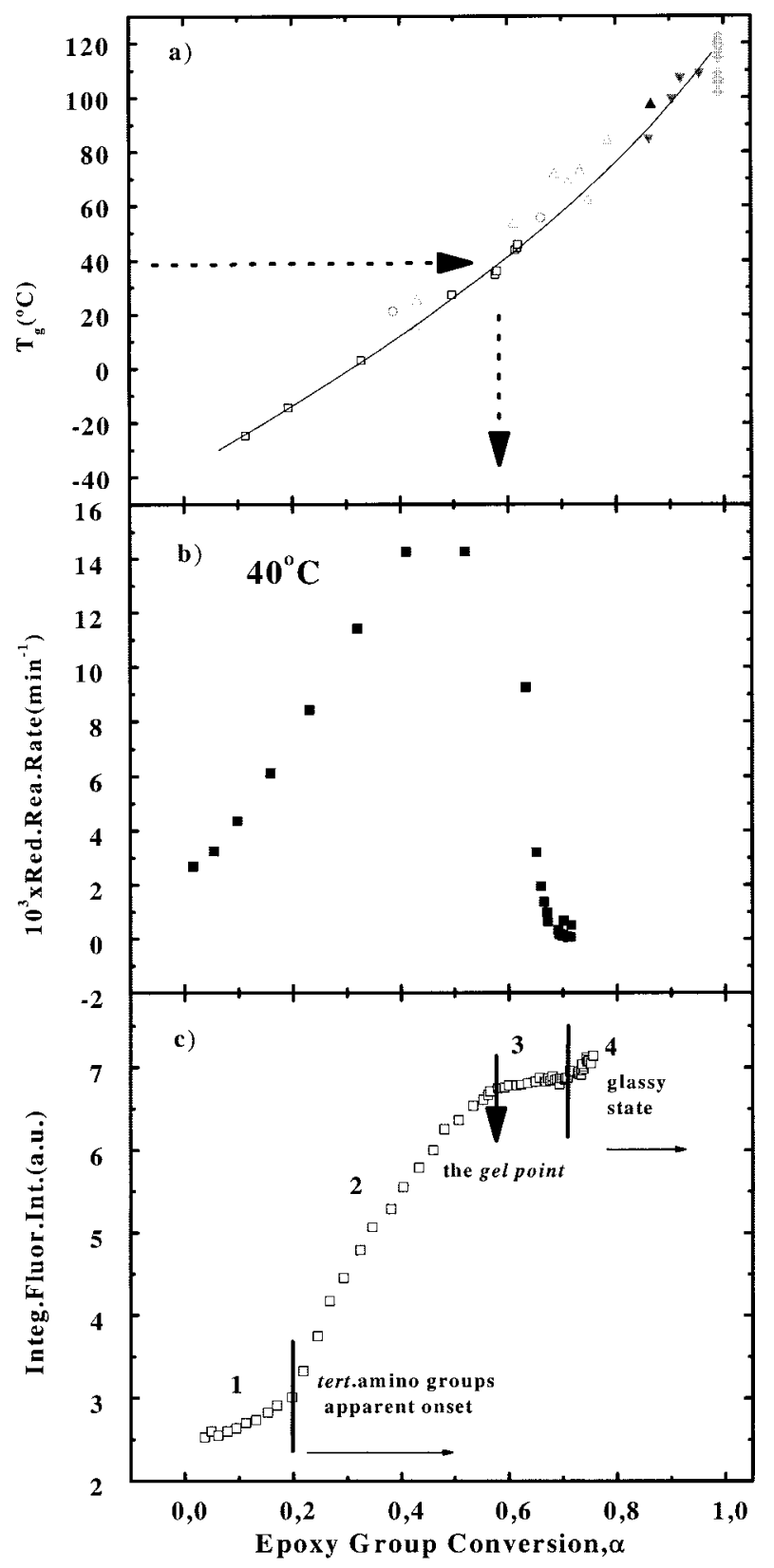

Figure 8. Dependence of (a) $T_{\mathrm{g}}$, (b) the reduced reaction rate, and (c) the integrated fluorescence intensity for the DNS label on $\alpha$ at $T_{\text {cure }}=40{ }^{\circ} \mathrm{C}$ for the stoichiometric reaction mixture DGEBA-EDA (for the symbols, see Fig. 7). 


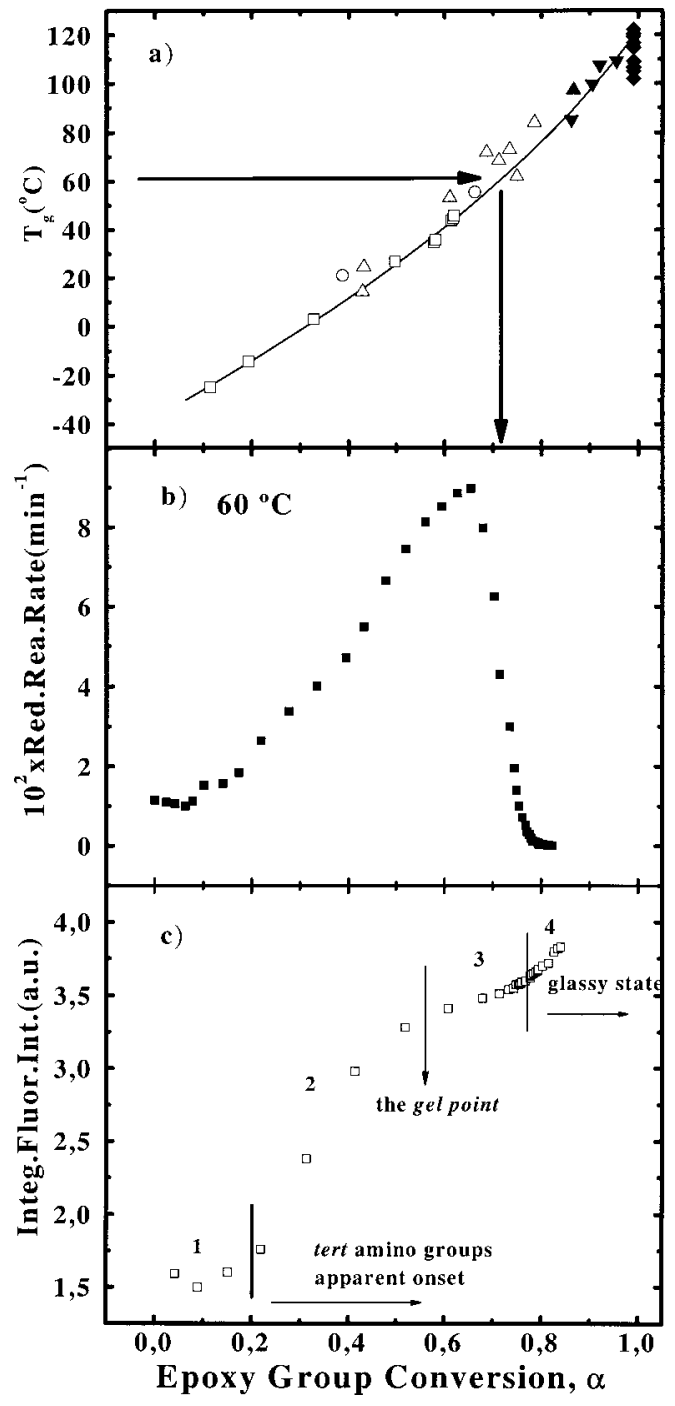

Figure 9. Dependence of (a) $T_{\mathrm{g}}$, (b) the reduced reaction rate, and (c) the integrated fluorescence intensity for the DNS label on $\alpha$ at $T_{\text {cure }}=60{ }^{\circ} \mathrm{C}$ for the stoichiometric reaction mixture DGEBA-EDA (for the symbols, see Fig. 7).

\section{Fluorescence Monitoring of the Curing Reaction}

The photophysical parameters of the DNS fluorophore that change during the curing are the fluorescence intensity, the wavelength at the emission maximum, the half-bandwidth, and the first momentum of the emission spectrum. ${ }^{22}$ In this work, only fluorescence intensity variations are discussed. The integrated fluorescence intensity has been evaluated as a function of $\alpha$ in the systems containing the DNS label or DNS probe.

\section{DGEBA-N, $N^{\prime}-D M E D A$}

The dependence of the integrated fluorescence intensity on $\alpha$ for the DNS label can be divided into several regions, the exact origins of which are not known [Fig. 10(b)]. It may be surmised that a wavy course of the dependence may reflect a different mobility of the DNS label attached to oligomers of different degrees of polymerization. The molecular weight distribution of the reaction products of the diepoxide and secondary diamine can be described by the most probable distribution. The molar concentration of polymer homologues with a polymerization degree $N\left(n_{\mathrm{N}}\right)$ referred to the initial number of moles $\left(n_{0}\right)$ in the system is given by $n_{\mathrm{N}} / n_{0}=(1-\alpha)^{2} \alpha^{N-1}$, and the maximum of this function is given by $\alpha_{\max }=(N$ $-1) /(N+1)$. For the dimer, $n_{2} / n_{0}$ exhibits a maximum at $\alpha=1 / 3$, which is the conversion range in which the slope of the integrated intensity passes through an inflection point. With increasing conversion, the molar concentration of polymer molecules of higher molecular weights increases. However, changes in the rotational and translational diffusion of micro-Brownian motion for the DNS label are expected to be largest between the monomer, dimer, and trimer molecules.

Table 2. Reaction Rate Constants for the Reaction of the Stoichiometric Reaction Mixture DGEBA with EDA

\begin{tabular}{ccccc}
\hline $\begin{array}{c}\text { Reaction } \\
\text { Temperature }\left({ }^{\circ} \mathrm{C}\right)\end{array}$ & $k_{2} / k_{1}$ & $\begin{array}{c}k_{1} \times 10^{4} \\
\left(\mathrm{~kg}^{2} / \mathrm{mol}^{2} \mathrm{~min}\right)^{\mathrm{c}}\end{array}$ & $\begin{array}{c}k_{1}{ }^{\prime} c_{\mathrm{o}} \times 10^{4} \\
(\mathrm{~kg} / \mathrm{mol} \mathrm{min})^{\mathrm{d}}\end{array}$ & $\begin{array}{c}k_{2} \times 10^{4} \\
\left(\mathrm{~kg}^{2} / \mathrm{mol}^{2} \mathrm{~min}^{\mathrm{e}}\right.\end{array}$ \\
\hline 20 & $0.42^{\mathrm{a}}$ & 4.1 & 1.6 & 1.7 \\
40 & $0.39^{\mathrm{b}}$ & 16.5 & 7.4 & 6.5 \\
60 & $0.39^{\mathrm{b}}$ & 73.6 & 7.9 & 28.7 \\
70 & $0.38^{\mathrm{b}}$ & 140.2 & 72.7 & 53.3 \\
80 & $0.38^{\mathrm{b}}$ & 236.9 & 77.9 & 90.0 \\
\hline
\end{tabular}

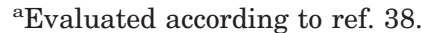

${ }^{\mathrm{b}}$ From ref. 38 .

${ }^{\mathrm{c}}$ Activation energy $=59.03$.

${ }^{\mathrm{d} A c t i v a t i o n}$ energy $=54.76$.

eActivation energy $=57.67$. 


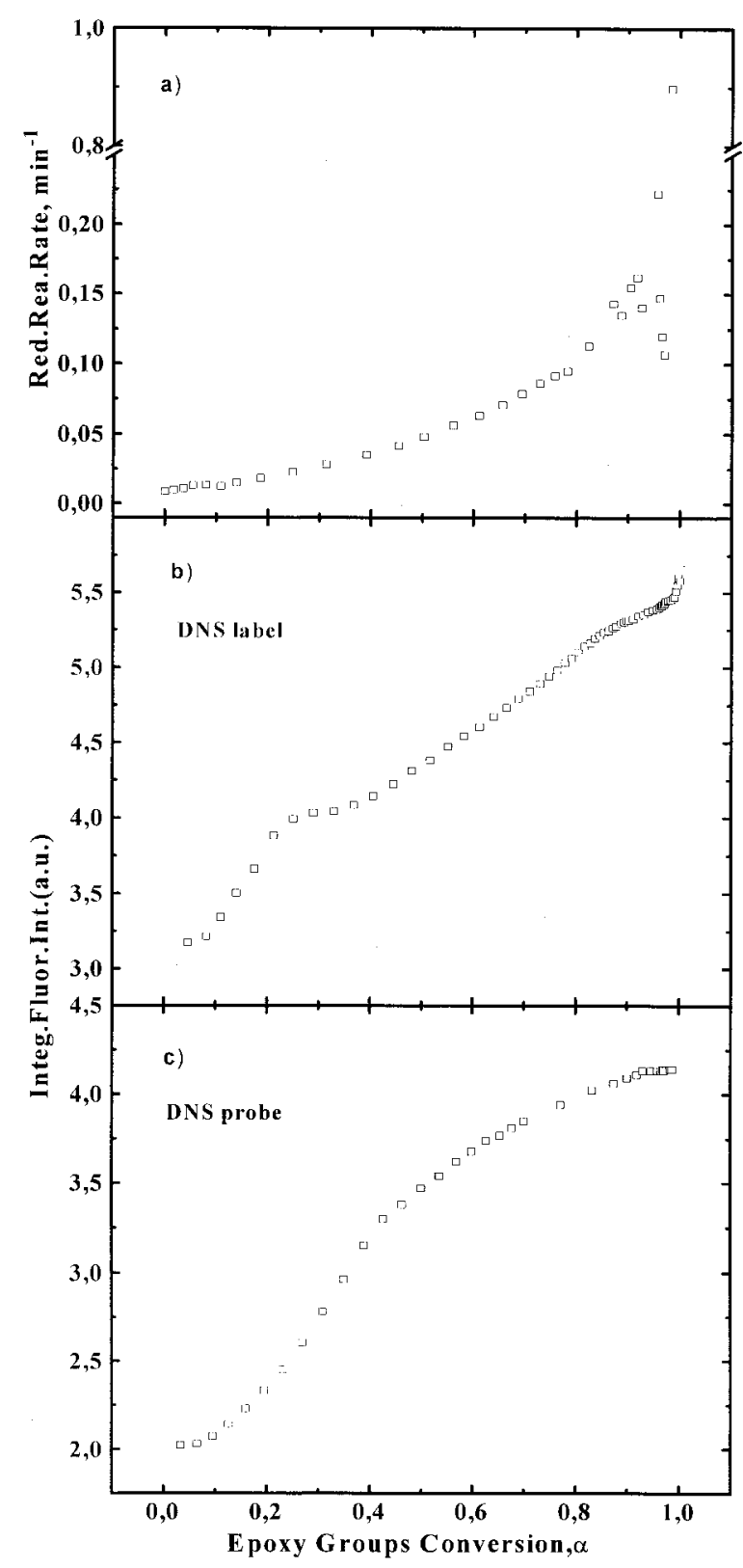

Figure 10. Dependence of (a) the reduced reaction rate (eq 4) and (b,c) the integrated fluorescence intensity for the DNS label and the DNS probe, respectively, on $\alpha$ for the stoichiometric reaction mixture DGEBA$N, N^{\prime}$-DMEDA at $40{ }^{\circ} \mathrm{C}$.

Therefore, a decrease in the dissipation of the excitation energy causes the largest increase in the integrated fluorescence intensity for low values of $\alpha$. The differences in the relaxation rates of the DNS labels attached to higher homologous oligomers will diminish. At $\alpha \sim 0.93$ (see Fig. 2), $T_{\mathrm{g}}$ is equal to $T_{\text {cure }}=40{ }^{\circ} \mathrm{C}$, and in agreement with the dependence of the reduced reaction rate on $\alpha$ at the same temperature [Fig. 10(a)], the system enters the vitrification region. A further steep increase in the fluorescence intensity at a very high conversion $(>0.98)$ characterizes entry into the glassy state.

Similar curing experiments were performed with the DNSd-Bu probe [Fig. 10(c)]. The most remarkable difference between the fluorescence behavior of the DNS label and DNS probe is the wavy course of the dependence of the fluorescence intensity only seen when the DNS fluorophore is attached to the polymer chain [Fig. 10(b)]. The final stage of the polyaddition reaction (at conversion $\sim 0.98$ ), which characterizes the boundary between the vitrifying reaction mixture and the glassy state, can only be detected if the fluorophore is a label. In the vitrified region $(\alpha>0.98)$, the mobility of the polymer chains is strictly limited. This imposes a severe mobility restriction on the DNS fluorophore chemically attached to the polymer chain. The decrease in the mobility of the DNS label brings about a further steep increase in the integrated fluorescence intensity. The fluorescence quantum yield of the DNS probe in the glassy state is not further affected, and this probably reflects the fact that the fluorophore environments are different for the label and the probe. Analogous dependencies have been obtained for the DNS label at 30 and $60^{\circ} \mathrm{C}\left(>T_{\mathrm{g}_{\infty}}\right)$ in the same system, except that the entry of the system into the glassy state does not occur at the reaction temperature of $60{ }^{\circ} \mathrm{C}$. For the probe DNSd-Bu at 30 and $60{ }^{\circ} \mathrm{C}$, the dependence of the integrated intensity on $\alpha$ is nearly the same as that in Figure 10 (c). Only the differences in the normalized intensities reflect the dependence of the fluorescence quantum yield of DNSd-Bu on the reaction temperature.

\section{DGEBA-EDA}

The integrated fluorescence intensity for the DNS fluorophore has been evaluated at certain curing time intervals and as a function of $\alpha$ at $T_{\text {cure }}=20$, $T_{\text {cure }}=40$, and $T_{\text {cure }}=60^{\circ} \mathrm{C}$. The dependence of the integrated fluorescence intensity on $\alpha$ for the DGEBA-EDA reaction system containing the DNS label is shown in Figures 7(c), 8(c), and 9(c).

This wide temperature range $\left(20-60{ }^{\circ} \mathrm{C}\right)$ leads to changes in the physicochemical properties of the system. In particular, a decrease in the viscosity of the reaction mixture at a higher reaction temperature has to be considered. Analogously, differences in the interactions between the fluoro- 
phore label, the growing polymer molecules, and the components of the reaction mixture serving as solvents are influenced by the reaction temperature.

The dependence of the integrated fluorescence intensity on $\alpha$ [Figs. 7(c), 8(c), and 9(c)] consists of several regions, but not every region can be clearly distinguished from the others at $T_{\text {cure }}$ $=20-60{ }^{\circ} \mathrm{C}$. Although an apparent onset of the tertiary amino groups at $\alpha \sim 0.2$ can be monitored at $T_{\text {cure }}=40$ and $T_{\text {cure }}=60{ }^{\circ} \mathrm{C}$, at $20{ }^{\circ} \mathrm{C}$, a monotonous increase in the integrated fluorescence intensity can be observed. The largest changes in the integrated fluorescence intensity occur in region 2 . The gel point at 40 and $60{ }^{\circ} \mathrm{C}$ is characterized by a decrease in the slopes of the curves [Figs. 8(c) and 9(c)] of the integrated fluorescence intensity versus $\alpha$. A similar trend has been observed at $40{ }^{\circ} \mathrm{C}$ for the nonstoichiometric reaction mixture DGEBA-EDA labeled with the DNS fluorophore (Fig. 11). Beyond the gel point, the increase in the gel fraction is accompanied by a moderate increase in the microenvironment viscosity of the DNS fluorescence label, which causes a moderate increase in the fluorescence intensity.

The system does not reach complete conversion, but at an $\alpha$ value that depends on $T_{\text {cure }}$, the system enters a boundary between the vitrifying region (region 3 ) and the glassy region (region 4). A further sluggish increase in $\alpha$ and progressive densification at a constant temperature bring about a continuing decrease in the mobility of the DNS label and, consequently, an increase in the fluorescence quantum yield of the DNS label.

For a comparison of the systems with the DNS label and DNS probe, let us inspect Figure 12. For $\alpha$ up to the gel point, these two dependencies are nearly identical. At the gel point, the normalized integrated fluorescence intensities for the systems containing the DNS label and probe show that the increase in the fluorescence intensity for the DNS probe is larger than that for the DNS label. The behaviors of these two systems are remarkably different in the following ways. The DNS probe detects neither the gel point nor the boundary between the vitrifying and glassy regions. Similarly, at 20 and $60^{\circ} \mathrm{C}$, neither the gel point nor the glassy state is detected by the DNS probe. However, a further increase in the intensity of fluorescence at the threshold of the glassy state for the system containing the DNS label can be observed. The fluorescence parameters reflect in some cases fundamental chemical and physicochemical changes caused by progress in the cur-
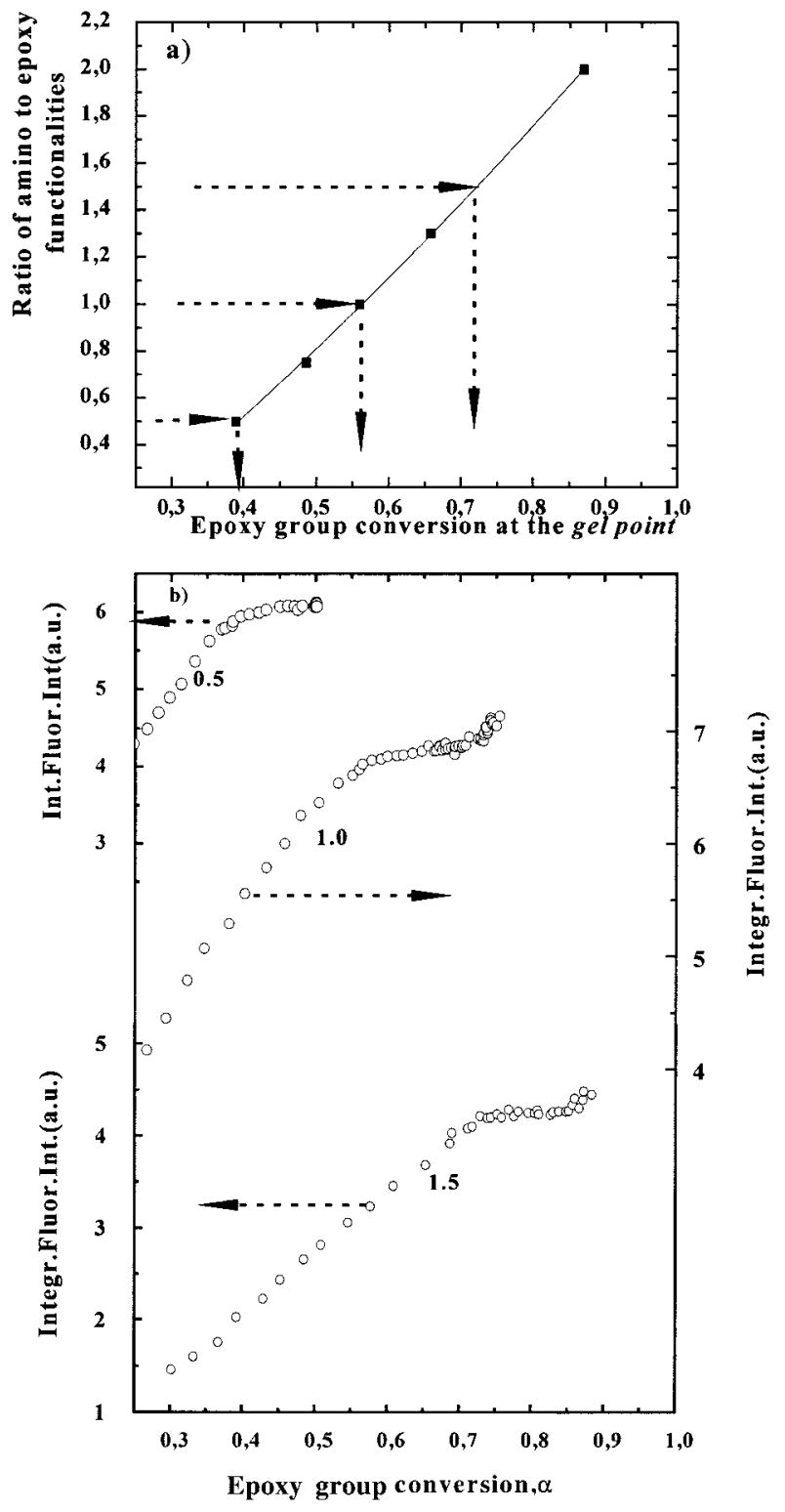

Figure 11. (a) Relationship between the initial ratio of amino functionalities to epoxy functionalities and $\alpha$ at the gel point and (b) the dependence of the integrated fluorescence intensity of the DNS label on $\alpha$ for the system DGEBA-EDA at $40{ }^{\circ} \mathrm{C}$. The numbers on the curves denote the initial ratio of amino functionalities to epoxide functionalities.

ing reaction. Nevertheless, not all changes caused by progress in the reaction can be detected at every $T_{\text {cure }}$.

\section{CONCLUSIONS}

The most pronounced changes observed in the integrated fluorescence intensity versus $\alpha$ are 


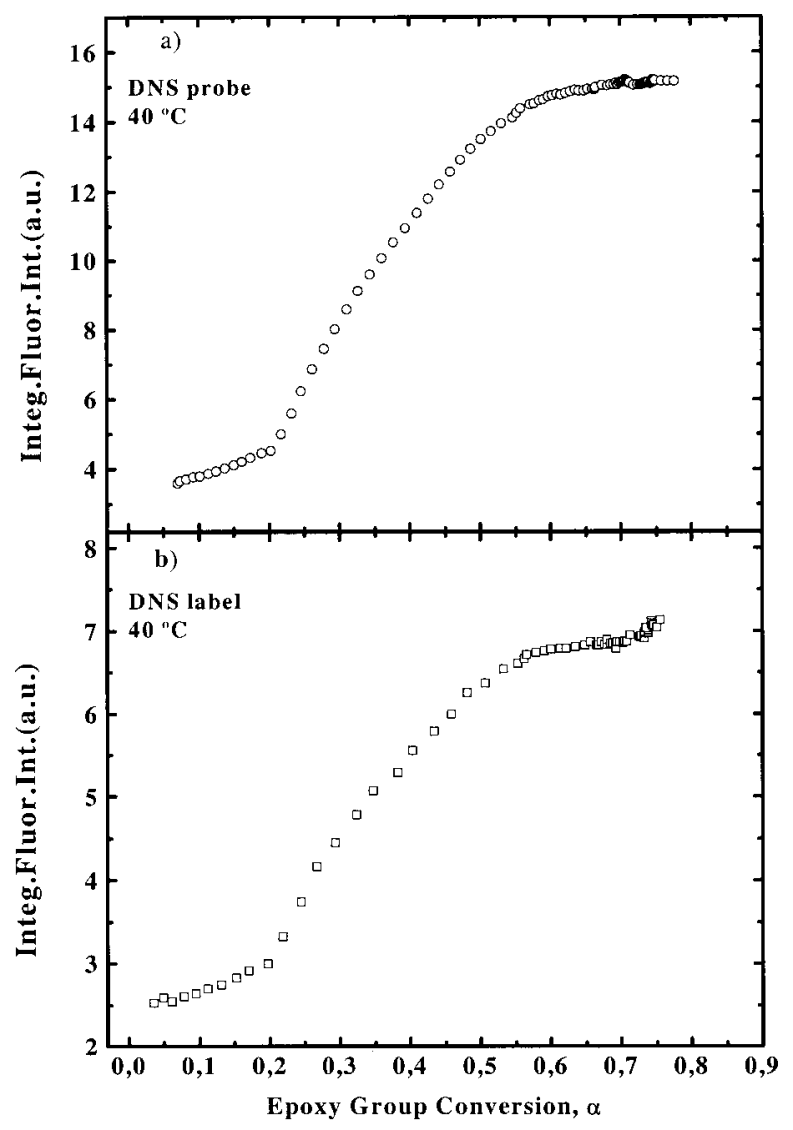

Figure 12. Dependence of the integrated fluorescence intensity for (a) the DNS probe and (b) the DNS label on $\alpha$ for the stoichiometric reaction mixture DGEBA-EDA at $T_{\text {cure }}=40^{\circ} \mathrm{C}$.

those observed for the curing system DGEBAEDA. The following phenomenological changes are of particular interest: (1) an apparent onset in the concentration of the tertiary amino groups in the system, (2) the progression of the branching reaction, (3) the gel point, and (4) $\alpha$ characterizing a boundary between the region of progressing vitrification and that of the glassy state. It is of particular significance that the DNS probe, in contrast to the DNS label, does not detect under the same experimental conditions the gel point or the entry of the system into the glassy state for the crosslinking systems examined.

The authors thank the anonymous reviewers for their constructive comments and the European Commission for funding through the BRITE-EuRam project (BE97-4472) and Comunidad Autónoma de Madrid (CAM)(07N/0002/98).

\section{REFERENCES AND NOTES}

1. Wang, F. W.; Lowry, R. E.; Fanconi, B. M. Polymer 1986, 27, 1529-1532.

2. Fanconi, B. M.; Wang, F. W.; Lowry, R. E. Rev Prog Quant Nondestruct Eval B 1987, 6, 1287-1293.

3. Strehmel, B.; Strehmel, V.; Younes, M. J Polym Sci Part B: Polym Phys 1999, 37, 1367-1386.

4. Sung, C. S. P.; Chin, I.-J.; Yu, W. C. Macromolecules 1985, 18, 1510-1512.

5. Sung, C. S. P.; Pyun, E.; Sun, H. L. Macromolecules 1986, 19, 2922-2932.

6. Sung, C. S. P.; Mathisen, R. Polymer 1987, 28, 941-945.

7. Yu, W.-C.; Sung, C. S. P. Macromolecules 1990, 23, 386-390.

8. Sung, C. S. P.; Pyun, E.; Sun, H.-L. Macromolecules 1986, 19, 2922-2932.

9. Pyun, E. Sung, C. S. P. Macromolecules 1991, 24, $855-861$.

10. Song, J. C.; Sung, C. S. P. Macromolecules 1993, 26, 4818-4824.

11. Paik, H.-J.; Sung, N.-H. Polym Eng Sci 1994, 34, 1025-1032.

12. Levy, R. L.; Ames, D. P. Polym Sci Technol 1984, 29, 245-256.

13. Chin, I.-J.; Sung, C. S. P. Macromolecules 1984, 17, 2603-2607.

14. Reichardt, C. Chem Rev 1994, 94, 2319-2358.

15. Paley, M. S.; McGill, R. A.; Howard, S. C.; Wallace, S. E.; Harris, J. M. Macromolecules 1990, 23, 45574564 .

16. Loufty, R. O. Macromolecules 1981, 14, 270-275.

17. Loufty, R. O.; Teegarden, D. M. Macromolecules 1983, 16, 452-456.

18. Jager, W. F.; Volkers, A. A.; Neckers, D. C. Macromolecules 1995, 28, 8153-8158.

19. Jager, W. F.; Kudasheva, D.; Neckers, D. C. Macromolecules 1996, 29, 7351-7355.

20. Mikeš, F.; González-Benito, F. J.; Baselga, J. J Macromol Sci Phys 2001, 40, 405-428.

21. Mikeš, F.; Baselga, J.; Paz-Abuín, S. Eur Polym J 2002, 38, 393-2404.

22. Mikeš, F.; González-Benito, F. J.; Serrano, B.; Bravo, J.; Baselga, J. Polymer 2002, 43, 4331-4339.

23. Paz-Abuín, S.; Pellín, M.; Núňez, L. J Appl Polym Sci 1990, 41, 2155-2167.

24. Urbansky, J.; Czerwinski, W.; Janicka, K.; Majewska, F.; Zowall, H. Handbook of Analysis of Synthetic Polymers and Plastics; Ellis Horwood: Chichester, England, 1977; p 302.

25. Dannenberg, H. Soc Plast Eng Trans 1963, 3, 78.

26. Morgan, R. Adv Polym Sci 1985, 72, 1-44.

27. George, G. A.; Cole-Clarise, P.; St. John, N.; Friend, G. J Appl Polym Sci 1991, 42, 643-657.

28. St. John, N.; George, G. A. Polymer 1992, 33, 2679 2688. 
29. Obtemperanskaya, S. J.; Khoe, N. G. Zh Anal Khim 1969, 24, 1588-1594.

30. Ranu, B. C.; Dey, S. S.; Hajra, A. Arkivoc 2002, No. 7, 76 .

31. Horie, K.; Hiura, H.; Sawada, M.; Mita, I.; Kambe, H. J Polym Sci Part A-1: Polym Chem 1970, 8, 1357-1372.

32. Riccardi, C. C.; Adabbo, H. E.; Williams, R. J. J. J Appl Polym Sci 1984, 29, 2481-2492.

33. Smith, I. T. Polymer 1961, 2, 95-108.

34. Sourour, S.; Kamal, M. R. Thermochim Acta 1976, 14, 41-59.

35. Rozenberg, B. A. Adv Polym Sci 1985, 75, 113-165.

36. Riccardi, C. C.; Fraga, F.; Dupuy, J.; Williams, R. J. J. J Appl Polym Sci 2001, 82, 2319-2325.

37. Flammersheim, H. J. Thermochim Acta 1998, 310, 153-159.

38. Paz-Abuin, S.; Lopez-Quintela, A.; Varela, M.; PazosPellín, M.; Prendes, P. Polymer 1997, 38, 3117-3120.

39. Ruseckaite, R. A.; Hu, L.; Riccardi, C. C.; Williams, R. J. J. Polym Int 1993, 30, 287-295.

40. Dušek, K. Adv Polym Sci 1986, 78, 1-59.

41. Williams, R. J. J. In Polymer Networks: Principles of Their Formation, Structure and Properties; Stepto, R. F. T., Ed.; Blackie: London, 1998; pp 94 and 109.

42. Dušek, K.; Havlíček, I. Prog Org Coat 1993, 22, 145-159.

43. Carrozzino, S.; Levita, G.; Rolla, P.; Tombari, E. Polym Eng Sci 1990, 30, 366-373. 